\title{
Solar Fuels and Next Generation Photovoltaics: The UNC-CH Energy Frontier Research Center
}

\author{
Thomas J. Meyer • John M. Papanikolas • \\ Catherine M. Heyer
}

Received: 11 October 2010/Accepted: 29 October 2010/Published online: 24 November 2010

(C) The Author(s) 2010. This article is published with open access at Springerlink.com

\begin{abstract}
The UNC Energy Frontier Research Center: "Solar Fuels and Next Generation Photovoltaics" is funded by a $\$ 17.5 \mathrm{M}$ grant from the US Department of Energy. Its mission is to conduct basic research that will enable a revolution in the collection and conversion of sunlight into storable solar fuels and electricity.
\end{abstract}

Keywords Solar fuels · Solar energy - Photovoltaics · EFRC · Catalysis

\section{Introduction}

On August 1, 2009 the UNC Energy Frontier Research Center in "Solar Fuels and Next Generation Photovoltaics" (www.efrc.unc.edu) began its life as a research center with a $\$ 17.5 \mathrm{M}$ grant from the US Department of Energy for five years. It is one of 46 EFRCs funded by DOE through its basic energy sciences (BES) division and the 2009 American Recovery and Reinvestment Act (ARRA).

The UNC EFRC is located at the University of North Carolina at Chapel Hill (UNC-CH) as a multi-faculty, integrated, collaborative research venture with participants in chemistry, physics and astronomy, and materials science at UNC-CH and faculty and staff collaborators at Duke University, North Carolina State University, North Carolina Central University, Research Triangle Institute, and the University of Florida.

The goal of the EFRC is to "Provide the basic research to enable a revolution in the collection and conversion of

T. J. Meyer $(\bowtie) \cdot$ J. M. Papanikolas · C. M. Heyer

Department of Chemistry, University of North Carolina

at Chapel Hill, Chapel Hill, NC, USA

e-mail: tjmeyer@email.unc.edu sunlight into storable solar fuels and electricity." The Center was constructed from existing research strengths at the partner institutions in chemical reactivity and catalysis, electrochemistry, semiconductors, polymers, and theory. A list of research accomplishments by the partners, cited in the initial proposal, is shown in Table 1.

Solar fuels and new approaches to photovoltaics were obvious themes. They had significant potential for breakthroughs that could enable solar energy to be viable. Both present unique research challenges requiring basic research breakthroughs and the ability to move them quickly to the marketplace.

Wide ranging research at this scale with an eye toward translation is not a characteristic of academic research centers. Our first discussions were about organization and structure. How could we utilize the strengths of academia and academic research to explore multi-dimensional, longrange research problems and bridge the gap to translation and real world applications?

The Center adopted the following Vision Statement:

Center Vision: The UNC EFRC will become a nationally and internationally recognized Center for breakthrough solar energy research. It will combine, in one management and support structure, the strongest features of research in academia and the national laboratories. From academia will come key personnel and the free-flowing exchange of ideas from all corners of the world in a cost-effective setting. From the laboratories will come continuity and focus on solving difficult scientific problems over extended periods. The UNC EFRC will build on existing research capabilities and incorporate new faculty and students to create a major center for energy research and teaching. 
Table 1 Research accomplishments in energy science at the University of North Carolina at Chapel Hill and its partner institutions

\section{SOLAR FUELS}

1. Excited state electron transfer

2. Chemical approaches to artificial photosynthesis

3. Chemically modified electrodes

4. Proton coupled electron transfer (PCET); its role in catalysis \& energy conversion

5. New catalysts for $\mathrm{C}-\mathrm{H}$ bond activation

6. First solution and surface-bound single-site water oxidation catalyst

7. First predictive theory of two-electron transfer with application to ATP energy transduction

8. First film-based catalysts for $\mathrm{CO}_{2}$ reduction

9. First Dye Sensitized Photoelectrosynthesis Cell (DS PEC)

10. Characterization of nanoparticles from electrochemical quantum capacitance \& band-gap measurements

11. Novel strategies for hierarchically assembled multifunctional nanostructures

\section{NEXT GENERATION PHOTOVOLTAICS}

1. Polymers and polypeptide oligomers for long range electron and energy transfer

2. First theoretical predictions-bridge structure influences electron tunneling; development of "tunneling pathways" for protein electron transfer

3. Breakthrough in molding materials for roll-to-roll manufacture of PV devices

4. High resolution soft lithography

5. Nanostructured titania-polymer photovoltaic devices

6. First 2-D nanostructural photonic enhancement of PV efficiency

7. Liquid crystal-mediated assembly of nonlinear optical materials

8. Scalable routes to $2 \mathrm{D}$ graphene

9. Nano-imprint lithography for manufacture of PV devices

10. Development of new density functional approximations to describe charge transfer

11. Design of molecules with optimal optical properties

We also knew that commercialization meant translation and incorporating translation into research design. With this in mind, we began discussions with the Research Triangle Institute (RTI www.rti.org). RTI was created by the three Research Triangle Park (RTP) research universities (Duke, NCSU, UNC-CH) in 1959. RTI has grown into one of the outstanding research institutes in the US with an annual research budget of $\$ 718 \mathrm{M}$ in 2009 . Research at RTI includes strong efforts in energy and semiconductors under the leadership of VP for Engineering and Technology, Dr. David Myers. A relationship between UNC EFRC and RTI continues to evolve combining EFRC research capabilities with RTI focus on engineering, energy, materials, and translation.
The UNC-RTI partnership in solar fuels was extended to our RTP partners Duke University and North Carolina State University led by the Research Triangle Energy Consortium (RTEC) led by Dr. Vikram Rao, formerly CTO of Haliburton. RTEC responded to a call by the Department of Energy last year for an energy efficiency "Hub" in solar fuels. It was one of three funded by Congress, at a level of $\$ 122$ million for five years. Although the RTECRTI-university proposal was unsuccessful, it led to the formation of a new RTP research consortium in solar fuels, the Research Triangle Solar Fuels Institute (RTSFI www.solarfuels.org) under the direction of Dr. James Trainham. Trainham is also a VP at RTI and is on the engineering faculty at NCSU. RTSFI is actively seeking to build a significant solar fuels research effort in North Carolina.

\section{The Research Challenge}

At a high level, the basis for our choice of research was driven by the realities and challenges in creating a new energy future. Substantial changes will have to be made in worldwide energy supply and use. Conflicting demands exist from a desire for growth-in the rapidly expanding economies of China, India, and East Asia-and energy availability. There is also a growing awareness of the adverse effects of energy production and use in global warming and environmental impact [1, 2]. Most of the world's energy supply, $\sim 85 \%$ in the US, comes from fossil fuels-natural gas, coal, oil. Increasing consumption of fossil fuels comes with an increasing risk from global warming and sea level rise as the atmospheric concentration of green house gases from burning fossil fuels rises. Our current transportation economy relies on oil but estimates of "peak oil", when oil production peaks and begins to decline, range from two years ago to 2025 [3].

There are many energy sources to draw on, but for environmental balance and energy sustainability, the most appealing source is the sun. It is the ultimate sustainable energy source. Its daily input to the earth is $\sim 10,000$ times current energy use. It is free of greenhouse gases and pollutants and secure without existing geo-political constraints. We use solar energy routinely to generate electricity from wind, waves, and hydroelectricity and they are all forms of concentrated solar energy. Direct solar energy from photovoltaics (PV) is another matter. In the US in 2008 , only $1 / 8 \%$ of US electric power production came from solar.

Even with its appeal, there are significant limitations to solar energy. It may be plentiful but it is also diffuse. Large surface areas are required for collection. The current energy power use in the US is three terawatts (TW). In 
order to achieve that level at $10 \%$ efficiency would require a land collection of area of $\sim 60,000$ square miles which is an area slightly larger than the state of North Carolina.

In a new solar economy, a fraction of the collection requirement would be met by using the roofs of existing and new construction but considerable additional area would be required to meet the needs of major urban areas and industrial complexes. The materials costs with current solar PV technology are staggering, $\$ 60$ Trillion for 60,000 sq mi based on conventional Si solar cells $\left(\$ 400\right.$ per $\left.\mathrm{m}^{2}\right)$. What we need is a new generation of inexpensive, carbonbased, $>10 \%$ solar efficient materials for use as "solar shingles" or "solar paint" which explains the UNC EFRC interest in "Next Generation Photovoltaics (NGPV)".

There is also an availability crisis. The sun may be plentiful but it is intermittent. It goes down at night. As an annualized global energy source, it has been estimated that, on the average, there are only $6 \mathrm{~h}$ of useful sunlight per day. If the sun is to succeed as our primary energy source, it will have to be coupled with energy storage on a massive scale. This is a problem shared with the existing electric power industry where a significant fraction of local demand for "peak power" - a cold January night in Boston, a late afternoon in August in North Carolina-could be met by energy storage and secondary power production instead of building more generating capabilities.

Current energy storage utilizes pumped hydro, compressed air, flywheels, batteries and super capacitors, but the scale for energy storage integrated with solar is prohibitive. Only the energy density in chemical bonds is adequate for storage at the required scale. Excess electrical capacity generated during the day could be stored chemically and utilized at night in existing power plants, or by secondary electricity generation in fuel cells.

An example is shown in Fig. 1. It shows the $\mathrm{CO}_{2}$ produced in a natural gas power plant captured, concentrated and transferred to a coupled solar reactor for water

$$
\begin{array}{r}
2 \mathrm{H}_{2} \mathrm{O}+4 \mathrm{hv} \rightarrow 2 \mathrm{H}_{2}+\mathrm{O}_{2} \quad\left(\Delta G^{o}=4.92 \mathrm{eV}, \mathrm{n}=4\right) \\
2 \mathrm{H}_{2} \mathrm{O}+\mathrm{CO}_{2}+8 \mathrm{hv} \rightarrow \mathrm{CH}_{4}+2 \mathrm{O}_{2} \quad\left(\Delta G^{o}=10.3 \mathrm{eV}, \mathrm{n}=8\right)
\end{array}
$$

Scheme 1 Solar fuel target reactions by artificial photosynthesis

reduction of $\mathrm{CO}_{2}$ back into methane. Combining the two would create a closed cycle with no release of "green house gasses".

Viable "solar fuel" targets include water splitting into hydrogen and oxygen, and water reduction of $\mathrm{CO}_{2}$ into almost any form of reduced carbon- $\mathrm{CO}$, formaldehyde, methanol, methane-with liquid hydrocarbons as an ultimate target. The chemical reactions for water splitting and reduction to methane, including the number of electrons transferred $(n)$, are shown in Scheme 1. Probably the first solar fuel available in large amount will be hydrogen because routes to water reduction to hydrogen are more straightforward than $\mathrm{CO}_{2}$ reduction. The promise of hydrogen as a transportation fuel may be limited, because of limitations in on-board hydrogen storage, but hydrogen could be used on site in large scale power generation. Also, when reacted with $\mathrm{CO}_{2}$, it is potentially a valuable feed stock for liquid fuels utilizing known technologies.

\section{Research in the UNC EFRC}

The UNC EFRC is conducting basic research on solar fuels and next generation photovoltaics. Our working credo is: "We will conduct basic research on possible devices for harnessing light/matter interactions and chemical processes for the efficient collection, transfer, and conversion of solar energy into fuels and electricity." This requires a broad, multidisciplinary approach in a highly collaborative setting drawing on expertise across a broad range of disciplines in chemistry, physics, and materials sciences.
Fig. 1 A closed cycle based on solar fuels and interconversion of $\mathrm{CO}_{2}$ and methane

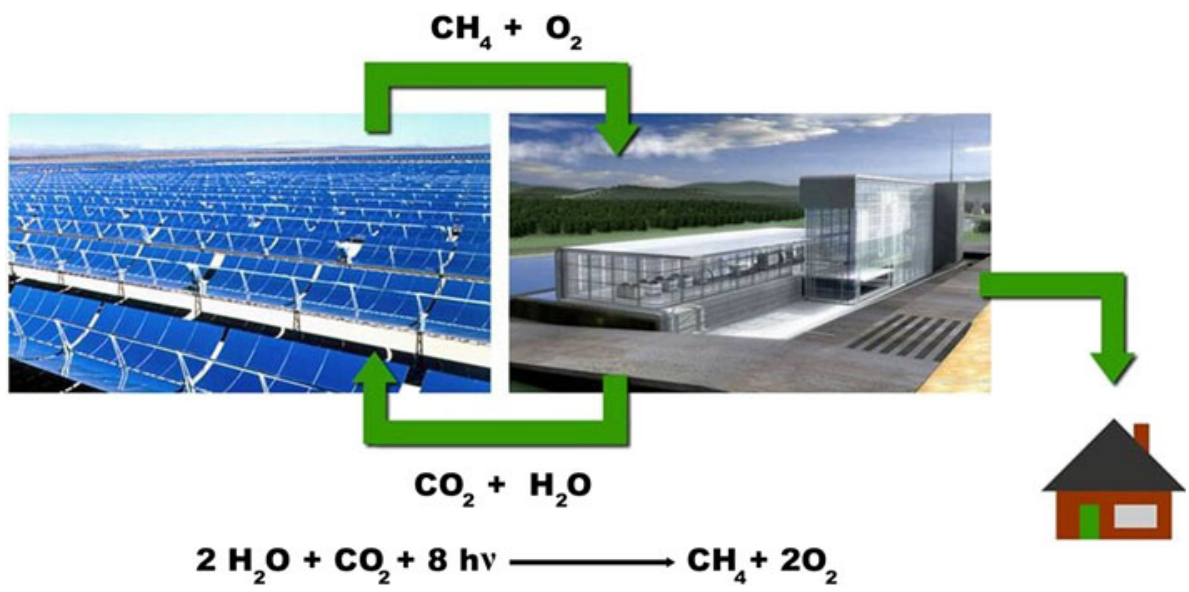


Fig. 2 Dye Sensitized Photoelectrosynthesis Cells for solar fuels production

\begin{tabular}{|l|l|}
\hline \multicolumn{2}{|c|}{ DYE SENSITIZED PHOTOELECTROSYNTHESIS CELLS } \\
FOR SOLAR FUELS PRODUCTION
\end{tabular}

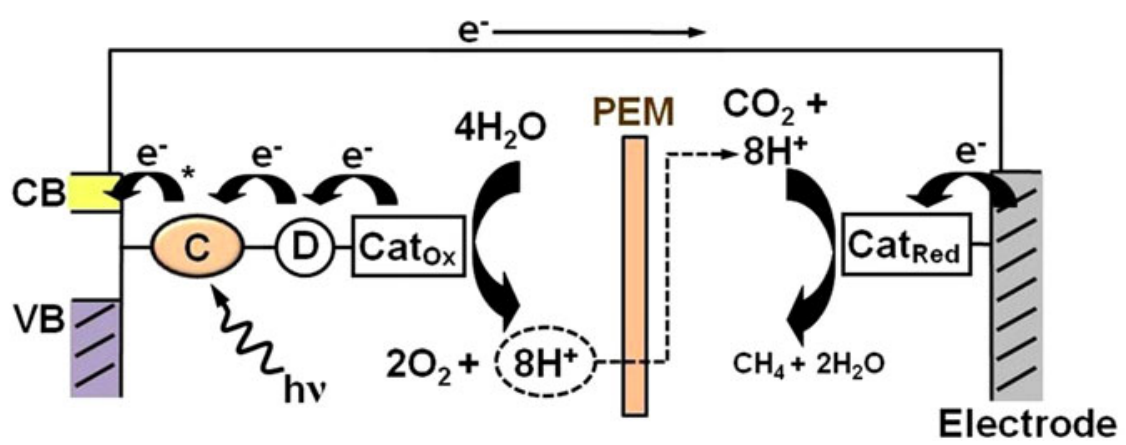

Fig. 3 Next generation photovoltaics

\begin{tabular}{|l|l|}
\hline \multicolumn{2}{|c|}{ NEXT GENERATION PHOTOVOLTAICS } \\
\hline $\begin{array}{l}\text { Component } \\
\text { Development }\end{array}$ & $\begin{array}{l}\text { Light-Harvesting Systems - High stability, efficient energy transport } \\
\text { Nanostructured Electrodes for Photovoltaic Applications }\end{array}$ \\
\hline Integrated Systems & $\begin{array}{c}\text { Integrated Assemblies - derivatized polymer \& polypeptide scaffolds with } \\
\text { multiple chromophores \& electron transfer donors \& acceptors } \\
\text { Surface Attachment - to semiconductor oxides }\end{array}$ \\
\hline Device Development & Next Generation Photovoltaic Devices \\
\hline
\end{tabular}

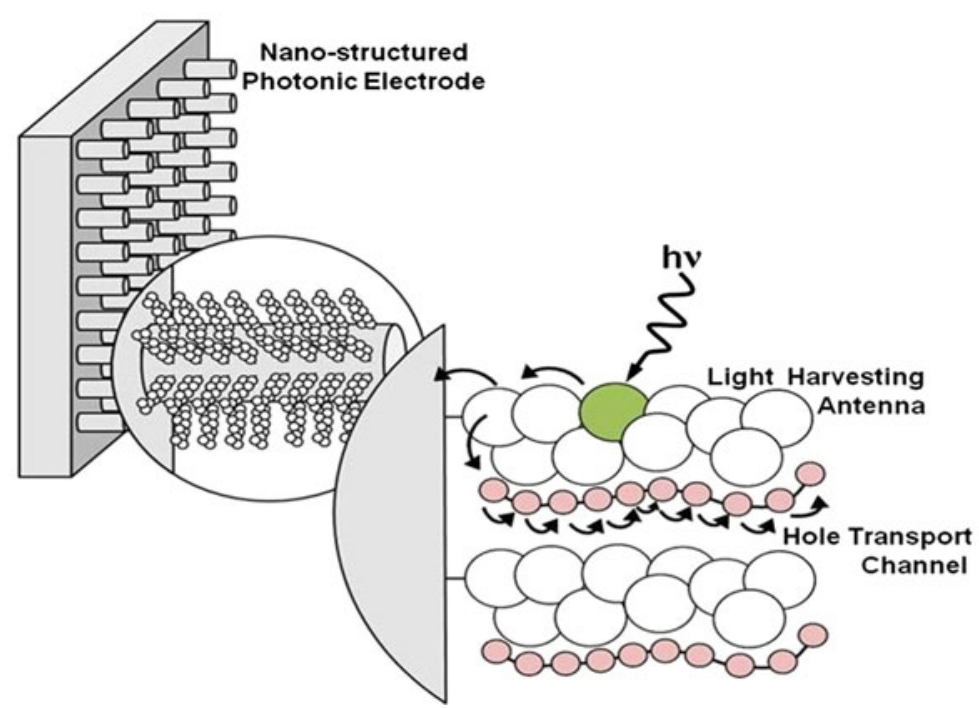

Two of our targets are illustrated in Figs. 2 and 3 together with a summary of current research for each. One is a Dye Sensitized Photoelectrosynthesis Cell (DSPEC) for solar driven water reduction of $\mathrm{CO}_{2}$, Fig. 2. The other is a structured, polymer-based PV device designed to exploit rapid one-dimensional electron and energy diffusion on a vertically structured $n$-type semiconductor acceptor, Fig. 3.
The DS-PEC device utilizes a modular approach and integration of multiple functions: molecular level light absorption; excited state electron injection into the conduction band of a semiconductor like $\mathrm{TiO}_{2}$; electron transfer activation of a catalyst for water oxidation by use of free energy gradients; physically separated catalysts for water oxidation and reduction with a separating proton exchange membrane (PEM) for proton diffusion and 
Table 2 Current research in the UNC EFRC

\section{SOLAR FUELS: CATALYSIS AND MATERIALS}

- Light absorption, electron transfer driven catalysis in molecular assemblies and composite materials

- Efficient devices for splitting water into $\mathrm{H}_{2}$ and $\mathrm{O}_{2}$, and reducing $\mathrm{CO}_{2}$ to methanol and hydrocarbons

\section{NEXT GENERATION PHOTOVOLTAICS}

- Structurally controlled molecular assemblies and composites

- Measurement and analysis of exciton dynamics, energy and charge transport

- Design of new interfaces amenable to roll-to-roll nanostructure fabrication

\section{ADVANCED SPECTROSCOPY AND THEORY}

- Supporting solar fuels and photovoltaics

- Cutting edge experimental methods and analysis of experimental data

- National and international leader in theoretical studies and in predicting and understanding scientific phenomena

Table 3 From basic science to devices

\begin{tabular}{|c|c|}
\hline \multirow{4}{*}{ SCIENCE } & Catalyst Design \& Development \\
\hline & Water Oxidation Catalysts \\
\hline & Carbon Dioxide Reduction Catalysts \\
\hline & Component Design \& Development \\
\hline \multirow{7}{*}{$\begin{array}{c}\text { Translational } \\
\text { Research }\end{array}$} & Light Harvesting Systems \\
\hline & Metal Oxide Electrodes \\
\hline & Integration \\
\hline & Light Harvesting/Catalyst Integration \\
\hline & Surface Attachment \\
\hline & Integration: Devices \\
\hline & Photoelectrosynthesis Cell Design \& Development \\
\hline DEVICES & Photovoltaic Cells \\
\hline
\end{tabular}

equilibration. The structured PV device exploits past findings demonstrating rapid intra-polymer energy transfer and interfacial electron transfer. Other novel approaches to PV devices are also being explored.

Table 2 presents a summary of key research areas and Table 3 is a flow chart which guides EFRC research from basic discovery to translation.

\section{Management, Oversight and Review}

The current participants-students, faculty, and institutions-in the UNC EFRC are listed in Table 4. It is an impressive group but diverse, and physically separated which places special demands on management and organization. Hallmarks of administrative success for us include the Center's ability to integrate, communicate, collaborate, educate, and translate-all with continuous review.
Table 4 Participants in the UNC EFRC

\section{PEOPLE}

26 Faculty, 7 Scientific staff, 13 Postdoctoral fellows, 20

Graduate students and 15 Affiliates

\section{UNC DEPARTMENTS}

Chemistry, Physics and Astronomy, Institute for Advanced Materials (IAM), UNC Research Computing Center, Renaissance Computing Institute (RENCI)

\section{INSTITUTIONS}

UNC, Duke University, North Carolina State University, North

Carolina Central University, University of Florida, Research

Triangle Institute (RTI)

\section{PARTNERSHIPS}

Research Triangle Institute, Research Triangle Energy Consortium, Research Triangle Solar Fuels Institute,

- The leadership team consists of: Tom Meyer (Director), John Papanikolas (Deputy Director), Catherine Heyer (Assistant Director), and Will Thauer (Executive Assistant).

- Oversight and decision making is provided by an Executive Committee which meets weekly and includes non-UNC representatives-David Beratan (Duke) and Kirk Schanze (Florida).

- The Research Council includes the research management team-Team Leaders who lead specific research areas (Water Oxidation, etc.) and Group Leaders who oversee major research areas (Catalysis, Semiconductors, etc.). They meet periodically to discuss resource allocations, review research, and provide guidance to the Executive Committee.

- The Research Teams meet every 1-2 weeks to review research results and plan for future research. These meetings are announced and open to all members of the EFRC. External participants have access through video teleconferencing.

- The Research Groups are made up of 2 or 3 Teams and meet monthly to integrate research, provide administrative and infrastructure support, and ensure collaborative opportunities and information sharing.

The teams are the functioning research units. They have: i) a shared vision, mission, and goals; ii) a collective understanding of and commitment to the Center; iii) the flexibility to respond and reorganize as scientific goals change; iv) the ability to innovate more rapidly than research groups with a single PI; v) the ability to extend the underlying science broadly and in new directions; vi) the ability to integrate a broad spectrum of ideas and capabilities.

The teams have complementary skills and capabilities in areas required for success. The keys to success are 
Table 5 UNC EFRC External Advisory Board

\begin{tabular}{ll}
\hline Héctor D. Abruña & Prof. Chem. \& Chem. Bio., Cornell Univ., NY \\
Michelle V. Buchanan & Assoc. Lab Dir., Phys. Sci., Oak Ridge NL, TN \\
Steven C. Freilich & Dir., Matl. Sci. \& Eng., CR \& D, E I DuPont, DE \\
Alexander L. Harris & Chair, Chem. Dept., Brookhaven NL, NY \\
David F. Myers & VP, Eng. \& Technology, Research Triangle Institute, NC \\
Arthur J. Nozik & Sr. Research Fellow, Nat. Renewable Energy Lab, CO \\
David G. Whitten & Prof., Chem. \& Nucl. Eng., U. of New Mexico, NM \\
\hline
\end{tabular}

communication, information sharing, and collective problem solving.

Center-wide meetings are held twice a semester, to review research progress by the individual research groups. There are presentations from different areas in an open format with questions and comments strongly encouraged.

In addition to administrative structure, significant attention has been paid to the development of a professional staff to support the research infrastructure, provide expertise, and ensure continuity. Their role in the center is vital in bringing: 1) support for and collaborations with individual investigators; 2) promoting research collaborations; 3) providing oversight and management of facilities, personnel, and safety; 4) ensuring continuity and flexibility in support of EFRC research; 5) instrument design, and development; 6) student mentoring, education, and training.

EFRC supported laboratories in laser spectroscopy and in materials preparation and characterization are in place but still evolving. In addition to initial DOE support, a congressional appropriation in 2010 has provided much needed flexibility in building multi-dimensional, versatile laboratories for spectroscopy and time resolved laser experiments, and for materials preparation and device fabrication. In addition to routine spectroscopies-Raman, surface FTIR, absorption, emission-the EFRC has, or is constructing, transient capabilities from the seconds to femtosecond time scales with UV-visible, EPR, emission, IR, and Raman monitoring.

The Fabrication Laboratory is focusing on preparation of nanomaterials and routine thin film samples and devices. The EFRC has access to a variety of surface analytical and fabrication tools through the UNC Institute for Advanced Materials (IAM), the Chapel Hill Analytical and Nanofabrication Laboratory (CHANL), and through collaborations at Duke, RTI, and North Carolina State University.

Given the diverse character of both the enterprise and its research, the EFRC was conscious from the beginning of the importance of oversight both internally and externally. Two formal advisory boards have been established. One, the UNC EFRC Internal Advisory Board, consists of the Chairs or Directors of Chemistry, Physics and Astronomy, the Institute for Advanced Materials, the Associate Dean for Science in the College of Arts and Sciences, and the
Vice Chancellor for Research and Economic Development at UNC. This group meets biannually, or as needed, to provide advice, review and insight into largely campusbased issues.

The second oversight group is the UNC EFRC External Advisory Board. It is a distinguished group of scientists and science managers, as can be seen by its membership (Table 5).

The EAB provides advice on operations and research in the Center on an as needed basis. It also participates in an annual research review, held in the spring with the first meeting held on May 11-12, 2010. The EAB provides an oral review and a written report to the Director and Deputy Director. The insight provided from the first EAB evaluation has been of great value in identifying areas that need focus and concentration of effort. Their input has provided a major impetus for important mid-course corrections in the research enterprise.

The annual EFRC research review is an internal review consisting of talks outlining progress by the research teams, posters describing individual research, and a social occasion for the members of the EFRC to congregate.

In addition to external reviews, the EFRC management team conducts an annual internal review of research areas and individual PI contributions with written evaluations sent to all participants. At the end of the first year, the combination of external and internal evaluations is being used to revisit goals and expectations and to develop strategic plans for each of the research areas of the Center for the coming year. We are looking forward to great progress in this and future years aided by this systematic approach.

\section{Looking Back at Progress Made and Ahead Toward the Future}

Much has been accomplished in the UNC EFRC in its first year of operation and we look forward to great things in the future. A quick summary of accomplishments would include:

- Creation of the UNC Energy Frontier Research Center; a vital, impactful organization that has provided 
leadership both at UNC and regionally in solar and related energy research.

- Development of structures and processes for successful, integrated research in an open, collaborative environment.

- Notable scientific accomplishments in key areas such as water oxidation, combining theory and experiment to elucidate reaction pathways, and development of new routes to semiconductor oxides for photoelectrochemistry. 15 papers have been published or are in the process of publication acknowledging EFRC support. Many more are in gestation.

- Utilization of leveraged support from other sources for EFRC programs and providing support for related areas.

- Creation of productive scientific collaborations and integrated research in $\mathrm{CO}_{2}$ reduction, photovoltaics, new semiconductor materials, and integration of theory and experiment that would not have existed without EFRC guidance and support.

- Initiation of industrial and regional partnerships.

- Hosting of a series of highly successful outreach events both to regional and national scientific audiences:

1. "Our Energy Future: Science and Technology Challenges of the 21st Century," Solar Fuels Meeting, Santa Fe, NM (Sept 1-2, 2009).

2. "Solar Fuels and Energy Storage: The Unmet Needs," UNC (January 14-15, 2010).

3. "A Sustainable Energy Future-Mapping the Way," Chapel Hill, NC (January 15, 2010). The latter was open to the public with more than 300 attendees and a panel discussion featuring the Speaker of the NC House of Representatives, Joe Hackney.

4. Presentations on energy issues to: US Congressman Mike McIntyre (9/2009); US Congressman David Price (2/2010); NC Board of Science \& Technology (11/2009); US Secretary of Energy Steven Chu (March 18, 2010).

The EFRC is proud of what it has accomplished in its first year of operation but is well aware that it is only a beginning. Strategic planning is currently underway to establish research goals for 2010-2011 in each of its research areas and for creation of an enhanced internal support structure. It is clear that $\$ 3.5 \mathrm{M} / \mathrm{yr}$ in funding provides a core of support but additional funding will be required to achieve our ultimate objectives and begin the process of translating basic research results to working devices.

We also look forward to a more outward looking focus as the Center matures and its results have an impact. This includes collaborations with other research centers in the US and abroad with contacts already in place with groups in Italy and Great Britain and with industrial laboratories with overlapping research interests. We also look forward to continued productive collaborations with our RTP partners and to helping to create a regional and national presence in solar energy research in the RTP area.

The goals are ambitious but we have begun and we look forward to great achievements in the future for the UNC EFRC.

Acknowledgment The UNC Energy Frontier Research Center EFRC: Solar Fuels and Next Generation Photovoltaics, is an Energy Frontier Research Center funded by the U.S. Department of Energy, Office of Science, Office of Basic Energy Sciences under Award Number DE-SC0001011.

Open Access This article is distributed under the terms of the Creative Commons Attribution Noncommercial License which permits any noncommercial use, distribution, and reproduction in any medium, provided the original author(s) and source are credited.

\section{References}

1. America's Climate Choices: Informing an Effective Response to Climate Change. National Research Council of the National Academies, National Academic Press, Washington, DC, July 2010, ISBN-10: 0-309-15774-9. http://www.nap.edu/catalog.php?record_ id $=12784$

2. United Nations Intergovernmental Panel on Climate Change IPCC (2007) Fourth assessment report: climate change, 2007 (AR4). http://www.ipcc.ch/publications_and_data/publications_and_data_ reports.htm\#1

3. Hirsch RL, Bezdek R, Wendling R (2005) Peaking of World oil production: impacts, mitigation, and risk management, a report sponsored by the National Energy Technology Laboratory of the US Department of Energy, http://www.netl.doe.gov/publications/ others/pdf/oil_peaking_netl.pdf 